The Version of Record of this manuscript has been published and is available in Cognition and Instruction, 6 April 2019, https://doi.org/10.1080/07370008.2019.1580711

\title{
Metaimagining and embodied conceptions of spacetime
}

\author{
Rolf Steier \\ Magdalena Kersting \\ University of Oslo
}

Keywords: Imagination, Embodiment, Physics Education, Sociocultural Theory, Gesture

To cite this article: Rolf Steier \& Magdalena Kersting (2019) Metaimagining and

Embodied Conceptions of Spacetime, Cognition and Instruction, 37:2, 145-168, DOI:

$10.1080 / 07370008.2019 .1580711$ 


\begin{abstract}
Though we live in a four-dimensional universe, our minds and bodies are not particularly good at perceiving and depicting four dimensions. This study contributes to our understanding of collaboration with abstract concepts by examining particular activities where bodily and experiential understandings may conflict with the conceptual domain. Specifically, upper secondary physics classrooms studying Einstein's general theory of relativity are taken as a setting to identify the representational practices and conceptual challenges that arise when learners attempt to make meaning with, and express conflicting notions of, space and time. To unpack these challenges, we draw on the concept of imagination and on theoretical perspectives that treat imagining as a social activity. We also present the concept of metaimagining to characterize layered processes in which learners attend to and manage shifts between their own imaginative activities. This concept is illustrated through a detailed analysis of an extended conversation between two upper secondary physics students working with general relativity and spacetime. The students perform a diverse set of imaginative activities that are strongly tied to communicative, cognitive, and bodily action. We also show how the unique domain of general relativity presents particular challenges to student meaning making of abstract concepts which in turn prompt metaimagining. Based on our analysis, we offer recommendations to improve instructional practices in general relativity and argue for the consideration of imagining as a transdisciplinary competency in math and science education.
\end{abstract}


Metaimagining and embodied conceptions of spacetime

\section{Introduction: Developing Imagination in Science Education}

This study takes the perspective of imagination as a social and interactional process as an entryway into understanding student approaches to abstract and difficult conceptual challenges in science classrooms. We draw on a body of literature, rooted in sociocultural theory, that considers the objects of imaginative activity to be materialized, embodied, and situated in the world as opposed to being restricted to the mental images of individuals (Nishizaka, 2003; Murphy, 2004; Hutchins, 2010; Pelaprat and Cole, 2011; Nemirovsky and Ferrara, 2009; Nemirovsky, Kelton, \& Rhodehamel, 2012; Zittoun \& Glăveanu, 2018). Accordingly, semiotic resources such as language, gesture, and material artifacts are the means through which imagination unfolds. The recognition that imagination can serve as an "organizational property of ongoing activity" (Nishizaka, 2003, p196) shifts the concept from the realm of the invisible and mysterious to one that is visible and even central to certain kinds of meaning making and disciplinary activity.

In the disciplines of science and mathematics, imagination is broadly recognized as being tied to innovation and the development of new ideas. Indeed, the history of natural sciences, and in particular the history of physics, abounds with examples of remarkable imaginative accomplishments:

When developing new theories [scientists] use the ability to imagine and visualise physical phenomena and 'play' with possible outcomes. Examples include simple analogies, as when Einstein, while working out the general theory of relativity, imagined what it would be like to ride on a ray of light and Faraday visualised electro-magnetic field lines. (Kind \& Kind, 2007, p. 22) 
It is not only in retrospect that one can identify imagination in scientific practice. Many scientists acknowledge that imagination constitutes a vital part in their work. Through multiple rounds of interviews with 25 scientists across a variety of disciplines, Osborne et al. (2003) found consensus on the statement that "Scientists, as much as any other profession, are passionate and involved humans whose work relies on inspiration and imagination" (p. 702). Despite this value placed on imagination in professional scientific practice, we still have very little understanding of where these practices come from and the roles that imaginative activities play in science classrooms (Egan, Judson, \& Madej, 2015; Kind \& Kind, 2007). We thus need a better understanding of the ways that students understand and incorporate imagining into their own science learning processes. To begin to address this challenge, we examine the forms of imagining that emerge between students in situated classroom interactions; situations where students are confronted with difficult imaginitive challenges.

Modern physics concepts such as general relativity present a particularly exciting opportunity for exploring such challenges and in particular the role of imagination in science classrooms. Aspects of general relativity present unique challenges for students and teachers because they contradict lessons from classical physics as well as students' everyday experiences. Accordingly, learners face the difficult task of aligning the perceptual qualities of concepts that defy their current lived understandings. When students are asked to give a qualitative description of the curvature of four-dimensional spacetime, they must draw on a repertoire of visualizations, gestures, models, thought experiments, etc. that defy or contradict aspects of the concept that they are attempting to understand. 
To explore this terrain, we address the following overarching research questions:

(1) What imaginative activities do students engage with to communicate and make meaning with abstract scientific concepts? (2) What insights for the teaching and learning of general relativity might be provided by attending to students' imagining?

In the following sections, we specify our approaches to imagining in relation to existing theoretical perspectives. We then extend these perspective through the concept of metaimagining, before turning to general relativity as a unique learning domain that supports investigations into particular imaginative processes. Finally, we present a methodological framework of embodied interaction as useful for investigating imaginative processes.

\section{Approaches to Imagining}

We focus on the kinds of imagining that occur between collaborators engaged in shared activity. At the most general level, imagining involves interacting with situations that are different from the present reality (Nishizaka, 2003; Zittoun \& Glăveanu, 2018). Imagining crosses temporal and spatial boundaries as participants shift between proximal and distal experiences (Hilppö et al., 2016). Importantly, imagining also includes attending to the consequences of these hypothetical situations, and participants engaged in imagining are identifying the implications of a given situation and extending the consequences of treating alternative possibilities as real. Nemirovsky et al. (2012) articulate this aspect of imagining as "[...] projecting a realm of possibilities that partially overlaps with the one we would project if we were facing a corresponding actual situation." Although there is a substantial body of research that considers these alternative situations to be expressed in the form of mental images, we orient this study 
towards sociocultural perspectives that focus on the publicly perceivable ways that participants organize their activity.

In this section, we review these perspectives by focusing on four key aspects which include considering imagining as (a) a socially situated activity, as (b) distributed in the material environment, as (c) internally and externally oriented, and as (d) deeply connected to meaning making processes.

First, in line with Murphy (2004), it is important to emphasize the active formulation of imagining as action as opposed to dealing with imagination as a static feature of individual cognition. This implies that imagining is an ongoing process, and by taking this stance, we are able to focus on patterns of participation through which imagining is performed. An implication of this stance is that the unit of analysis shifts away from the individual's mental images or visualizations that occupy a significant thread of imagination research (Nishizaka, 2003). This is not to argue against the "image", but rather to emphasize the developmental and experiential aspects of imagining. Nishizaka (2003) argues that mental images are often problematically intertwined with imagining.

Indeed, one often imagines the 'non-imageable and non-picturable'; one can imagine, for example, that the Crucifixion is the redemption of human beings, or how to solve a mathematical problem. Furthermore, even when one imagines something by having its image, having the image is not imagination per se. Imagining Mary is different from imagining her identical twin Martha even though their images are identical. It is crucial to avoid conflating imagining and 
having a mental image. Their conflation causes further serious confusions. (p.

Treating imagination as an "organizational feature of activity" (Nishizaka, 2003) allows us to attend to the ways that the abstract, invisible, non-present are made to be present.

Second, imagining is regarded as distributed in the material environment in that it may be performed by a group of co-participants through a variety of publicly available forms and signs (Hutchins, 2010; Jornet \& Steier, 2015; Murphy, 2004; Steier, Kersting, \& Silseth, in press). These may include words, gestures, material representations, etc. As researchers, we can thus attend to these productions and resources, not as reflections of the cognitive structures of imagination, but as mediators of the process of imagining (See Wertsch, 1998 and mediated action). In this sense, the activity of imagining may be considered as related to practices of representation (Hall, 1996). That is, representational practices are one possible means to facilitate imagining in that participants collectively attempt to make the not-present perceivable to each other. In a social setting, these attempts may be attributed to the group - either because a representation may be coconstructed, or because its production depends in some way on the reception by the collaborator.

However, the stance that imagining involves publicly perceivable action does not necessitate that an imaginer is solely oriented towards co-participants. A third aspect of sociocultural approaches to imagining is that it is both internally and externally oriented. We draw on Vygotsky’s (1978) connection between cognition on the intramental plane, and communication on the intermental plane as being united in the development of sign meaning. That is, these publicly available signs, as mediators of imagining, may serve as 
shared resources for the group while still being produced by an individual to mediate their own cognitive processes. (Alternatively, activities and signs intended to communicate with co-participants may also mediate individual cognition.) For example, one may temporarily imagine that a basketball is the Earth in order to construct the shortest path an airplane would travel from Europe to North America (Steier, Kersting, \& Silseth, in press). The fact that this imagining is perceivable by potential collaborators (and possibly invites shared contributions) does not necessitate that one is actively engaging in this imaginative activity for them; this imagining may be performed with the intention of mediating one's own thinking. Similarly, a child using her fingers to count may be orienting this activity towards her own cognitive processes while also performing socially in a way that allows a teacher to intervene and support. Thus when we characterize imagining as internally and externally oriented, the implication is that these aspects are not exclusive but intertwined.

Finally, it is also important to emphasize that imagination is connected to learning. We draw on Vygotsky's (1998) view of imagining as a fundamental feature of meaning making:

Moreover, according to the valid observation of Pushkin, imagination is as necessary in geometry as it is in poetry. Everything that requires artistic transformation of reality, everything that is connected with interpretation and construction of something new, requires the indispensable participation of imagination. (p. 153)

In the context of mathematics learning, Nemirovsky and Ferrara (2009) characterize imagining as "entertaining possibilities for action; entertaining (in the sense of "holding" 
or "keeping") a state of readiness for the enactment of possible actions" (p159). This view highlights the perceptuo-motor aspects of imagining and demonstrate how imagining involves working through the possible consequences of a particular situation. In the episode presented in detail for this study, we see at one point a student ask his partner to imagine placing a ball on a slope. The intention here is not to create a static image, but rather to open up an opportunity to think through (to imagine) the possible consequences of the given situation. This readiness to perform a bodily action in mathematical thought is also highlighted by Lakoff and Núñez (2000), who suggest that bodily action may be a key aspect of mathematical thinking.

The ways that participants work with these possibilities for action are central to imagining. In particular, imagining involves the unification of conflicting or disjointed aspects of experience into a perceivable whole. Pelaprat and Cole (2011) characterize this unification process by focusing on the "gap-filling" process between such possibilities: Imagination is the process of resolving and connecting the fragmented, poorly coordinated experience of the world so as to bring about a stable image of the world. Thereby a feeling of oneself in relation to the world emerges. (p. 399) Similarly, Nemirovsky and Ferrara (2009) introduce the concept of 'juxtaposing displacements'. This concept describes imagining as involving the depiction of several seemingly disjointed aspects of a given situation:

Rather than animating scenes from a single point of view, such as an unedited regular photo shoot does, the imaginary activity appears to jump from one point of view to another, making the simultaneous sequential, and altering the temporal order of events. The unity of all these glimpses - the unity lived by the imaginer 
and her listeners - emanates from their ongoing juxtaposition in the imaginers' lived space and time. (p. 167-168)

In other words, meaning making as imagining involves efforts to bring forth the unexperienced, immaterial, or non-present by bringing together disparate aspects of the object of imagination into a perceivable or communicable whole.

This non-linear jumping between signs and perspectives begins to characterize the ways that participants may approach imaginative challenges through successive and iterative practices. However, collectively, literature from these sociocultural approaches does not adequately deal with situations in which imagining is challenging, impossible, or contested. What occurs when participants confront their own imaginative practices or their own imaginative limitations? How do learners respond when they encounter a concept or situation that cannot be immediately imagined or that cannot be expressed in a way that allows for the exploration of possible consequences?

The characterization of imagining as improvisational in particular social and environmentally situated contexts raises questions about how imagination may be developed or considered as an object of instruction. Making this instructional turn necessitates that we have a better understanding of the tensions that arise when imagining breaks down among participants.

In the next section, we introduce the exploratory concept of metaimagining to unpack and make sense of situations in which participants confront challenges, assumptions, and the very contexts of their own processes of imagining. 


\section{Metaimagining}

In the course of analyzing the imaginative processes presented in this study, we began to find that existing perspectives on imagining do not adequately deal with the distinction between its explicit and implicit forms. If explicit imagining occurs when participants intentionally introduce imaginative practices into their activity, implicit imagining is more subtle, and emerges without the participants attending to their own imagining. When learners are confronted with a difficult imaginative challenge, where they have difficulty expressing the consequences and possibilities of an alternative situation, the participants' imaginative processes may shift from being implicit and backgrounded, into an explicit, foregrounded aspect of the ongoing activity. In such cases, participants may be forced to consider the various assumptions, contexts, and frameworks within which their ongoing imaginative processes are unfolding. To help us make sense of such cases, we propose the concept of metaimagining, which characterizes the layered processes in which learners attend to and manage shifts between their own imagining activities.

It may be helpful to illustrate this concept with an example, so we turn to a rather well-known case explored by Hutchins in his groundbreaking book, Cognition in the Wild (1995) between Western and Micronesian navigation systems (see pp. 78-93). The description is actually a reinterpretation of an earlier account between Lewis (1972) and a Micronesian navigator named Beiong ${ }^{1}$. In this episode, Lewis seeks help identifying an island, and to communicate this island to Beiong, Lewis draws a bird's-eye view (map) of this island in relation to two other known islands. The trajectories between the three

\footnotetext{
1 We present a simplified version of this account. See Hutchins (1995) for a much more detailed summary and discussion.
} 
islands form a triangle. A communicative breakdown occurs because this bird's eye / map based system of Lewis (as a Western navigator) does not align with the Micronesian navigator's "boat's-eye” system. Thus an imaginative challenge emerges as Beiong and Lewis attempt to imagine the location of an island using two conflicting representational systems. We characterize this as an imaginative challenge (i.e., collectively imagining the location of an island while using two different reference systems) in that it leads the participants to examine assumptions about how they move and perceive in the world. This breakdown also serves as an entryway to metaimagining.

To overcome this challenge, Beiong "had to imagine himself to be at both ends of the voyage at once" (Hutchins, 1995, p80). Beiong placed himself at each of the two known islands on an imaginary journey to the other, while noting how the objects on the horizon would (hypothetically) move in relation to each other. In doing so, he could confirm that trajectory lines intersect at the third island that Lewis sought to identify. This additional layer of imagining, the perceptual experience of journeying between the islands (in both directions!), emerged as a way to address the challenge of imagining the location of the third island while using two different reference systems. We thus characterize this broader episode as a case of metaimagining. To put it in another way, Beiong and Lewis were initially engaged in one layer of imagining the location of an island that was not presently visible. The metaimaginative turn develops from the breakdown and subsequent recognition of their conflicting reference systems prompting Beiong to introduce the new layer of imagining as sailing between the islands. The prefix 'meta-' is used to recognize these multiple layers, and to highlight the distinction between 
simply imagining something, and reflecting on and responding to limitations of that first instance with the purposeful introduction new imaginings.

Metaimagining is an important concept because it opens up possibilities for articulating the epistemological and ontological challenges of participants attempting to integrate conflicting conceptual frameworks, when confronting the limits and assumptions of one's own imagining. Metaimagining may draw on other practices, such as thought experiments, analogies, or representations, and we characterize these practices and artifacts as metaimaginative productions. Such productions are considered to be mediators of metaimagining.

Accordingly, metaimagining is related to other concepts in the learning sciences. Just as metarepresentational competence (MRC) (diSessa, 2004) allows for the introduction of diverse representational practices as an object of instruction unrestricted to a particular discipline, metaimagining brings attention to an array of imaginative activities. Also, metarepresentational practices may in some cases function as metaimaginative when the practices are introduced in response to imaginative challenges. That is, metaimagining can certainly involve thinking about and shifting across forms and genres of representation, if such activity occurs in the context of mediating imaginative processes. In the episode presented in this study, we will see both an improvised sketch and scientific illustration function as mediators of imagining for a pair of students. Importantly, metaimagining is not limited to the use of representations in the strictest sense, as productions such as thought experiments, embodied performances, or metaphors can also serve as mediators of imagining. 
Metaimagining might also be considered metacognitive in that it involves participants attending to their own psycho-social processes. However, metaimagining is not merely thinking about imagining, or imagining about imagining. Rather, we call for a more nuanced concept that brings attention to the limits, boundaries, and assumptions of one's own imagining thus expanding the horizons of possible imaginings.

We know very little about how and what productions emerge when students reflect directly on their own processes of imagining as a means for making meaning of a particular concept or framework. We thus wish to deepen our understanding of imagining by attending to situations in science learning where imagining is central to the task at hand. This turn then opens up possibilities for addressing imagination more explicitly as an object of instruction (which we take up at the conclusion of this study).

\section{General Relativity as Imaginative Challenge}

General relativity provides a rich setting to study imaginative processes in physics classrooms. Combining a variety of conceptual challenges, Einstein's theory stimulates imagining in unique ways. While in recent years physicists and science educators have argued for introducing general relativity to undergraduate and high school curricula, initial efforts to do so have mostly focused on the development of teaching approaches rather than to look at students' experiences and learning processes (eg. Kaur, Blair, Moschilla, Stannard, \& Zadnik, 2017; Kersting, Henriksen, Bøe, \& Angell, 2018; Stannard, 2018; Velentzas \& Halkia, 2013). Consequently, student meaning making processes, including the role of imagination and its emergence, have been largely overlooked. 
Before demonstrating why general relativity is a suitable learning domain to investigate processes that prompt imagining, we want to provide a brief sketch of the theory's rationale. Introducing the idea that gravity is not a force, but a manifestation of the geometry of the universe, Einstein set the stage for the development of modern physics. Whereas time and space are static features in classical physics, general relativity describes the relationship between space, time, and gravity by merging time and space into a dynamic four-dimensional fabric called "spacetime". Gravity is interpreted geometrically through the notion of curvature: Mass curves spacetime and curvature influences the movement of mass (Wheeler, 1998). In this setting, the classical gravitational force becomes obsolete. What we experience as "force" is actually evidence for warped space and warped time around us. There is no force acting on Newton's apple falling down to earth - the apple just happens to follow a straight line through curved spacetime (Gould, 2016). However, we are not able to perceive this distortion of spacetime directly. Therefore, Einstein's insight overcame the established idea of a gravitational force. He revolutionized classical physics in defiance of us not being able to see or feel the intrinsic source of gravity.

Metaimagining arises out of contexts when learners confront imaginative challenges by attending to and manipulating shifts between their own imaginative activities. The domain of general relativity is uniquely positioned to facilitate such engagement. By intertwining several conceptual challenges in an unusual way, the theory prompts imaginative contexts to overlap. At the root of these of conceptual struggles lies the advanced mathematical framework of the theory (disessa, 1981; Wald, 2006) that invites learners to draw on visualizations and representations to obtain a qualitative 
understanding of the abstract concepts. Yet, those representations challenge learners' imaginative faculties. Our conceptual systems are three-dimensional and most representations are two-dimensional, but spacetime is a four-dimensional object that is not fully representable in two or three dimensions.

Translating between dimensions has been identified as a notorious problem for novices in fields such as astronomy or geography. The universe looks flat; extrapolating from two-dimensional representations to three-dimensional realities requires astronomers to master discipline-specific ways of moving between two and three dimensions (Eriksson, Linder, Airey, \& Redfors, 2014). This spatial awareness has become second nature for astronomers and astronomy educators, but Eriksson et al. observed that astronomy students struggled to make sense of the three-dimensionality of the Universe. Likewise, Azevedo and Mann (2017) described the conceptual work that is required to observe celestial objects as a complex activity that they termed "seeing in the dark". Seeing in the dark involves a strong reliance on the body that is used as a resource for practical, conceptual, and communicative purposes. This conceptual work requires learners to gesture towards imaginary points in the night sky, to draw imaginary lines between celestial bodies, or to read out star charts and maps of the sky.

An analogous dimensional challenge is present in the field of geography when geographers move between two-dimensional maps as representations (projections) of a three-dimensional world. Anderson \& Leinhardt (2002) found that expert geographers performed better than novices at a task using maps to find the shortest distances between locations on the earth's surface. Expert geographers were able to apply "visualization strategies" when working with maps as a means to deal with the distortions inherent in 
map projections. Whereas astronomy and geography requires imaginative practices to translate between two and three dimensions, general relativity moves the conceptual challenge to yet a higher-dimensional setting. By embedding gravitation into the context of four-dimensional spacetime, general relativity dramatically heightens the conceptual demands and thus allows us to study more complex processes of imagining.

In addition to the multidimensional nature of its conceptual domain, general relativity seems to entail a disorienting change of viewpoint similar to Hutchins' description of the two navigators (1996). Hutchins describes the contrast between the reference systems used by Micronesian and Western navigators and how their choice of representation limits their understanding of the situation. Whereas Micronesian navigators place themselves at a fixed center of a reference system with islands moving along the horizon, Western navigation depends on a fixed earth (represented by a map) with a ship's location constantly shifting. Similarly, Newton and Einstein proposed two different conceptual frameworks of space and time to describe the very same phenomenon of gravity. Just like Micronesian navigators struggled to reconcile their moving-island conceptions with the relative locations of those islands on an imaginary map, shifting between Newtonian and Einsteinian conceptions of gravity similarly involves dramatic ontological changes in spatial systems. Crosswalking different conceptual models of gravity requires a sophisticated understanding of one's own position in relation to the reference frame employed to describe the phenomenon. For learners, the Newtonian framework might be a more natural setting to pose questions and explore models of gravitation just like the bird's-eye view came more naturally to Western navigators (Hutchins, 1996). 
The apparent naturalness of the Newtonian description of gravity is closely related to another perceptual challenge that students encounter in the domain of general relativity. The relativistic notion of curved spacetime might contradict students' experiential understanding of the force of gravity. In particular, Einstein's description is not consistent with deeply rooted knowledge that stems from classical physics education. Kapon and diSessa (2012) found that students took the attraction of gravity for granted and often invoked the common explanation of "gravity pulls things downwards". Thus, general relativity presents students with an explanation of gravity that seems to come with an inherent contextual conflict. Students need to perform a considerable imaginative effort to overcome their experiential understanding of gravity, space, and time.

In light of imaginative challenges, scientists and science educators often rely on the use of analogies as a powerful means to access abstract topics (Harrison \& Treagust, 2006; Kapon \& diSessa, 2012). In general relativity, one of the most prevailing analogies of curved spacetime is the so called rubber sheet analogy that compares the fabric of spacetime to a rubber sheet bending under the influence of objects being placed on it (see Figure 1). While this analogy is heavily used in popular science literature and textbooks, many physicists and science educators criticize the analogy for being misleading, because it conveys a problematic understanding of gravity and curvature (diSessa, 1981; Gould, 2016; Kersting \& Steier, 2018). In the episode we present in this study, the rubber sheet analogy serves to prompt students' shared exploration of different conceptual models of gravity to make present what is not present, to visualize the invisible, in short to imagine gravity as curvature of four-dimensional spacetime. 


\section{Methodological Approach: Embodied interaction as an analytic framework in physics and mathematics learning}

There are parallel tensions within the domains of imagining and of embodied meaning making. A key distinction has been made in the literature on imagining between dealing with the mental image as a cognitive structure within the mind of an individual, and with imagining as an activity that is situated in social and material contexts. Similarly, approaches to embodied learning - and in particular, gesture - have made the distinction between bodily action as either a material reflection or simulation of an individual's cognitive structures on the one hand, and as a sociocultural activity that essentially is a form of meaning making on the other. Attempts to reconcile these tensions are taken up as a current challenge in the learning sciences (diSessa, Levin, \& Brown, 2015). Though in this study we adopt what would generally be characterized as an interactionist methodology, we use these parallel tensions as an entryway into our methodological approach.

We use embodied interaction (Streeck, Goodwin, \& Lebaron, 2011) as a general analytic approach to understanding situated classroom interaction. This approach lets us take as a unit of analysis the bodies of actors, their talk, as well as their shifting relationships to each other, the local setting, and resources. This approach (and other similar approaches) has revealed that, "action is built through the mutual elaboration of diverse semiotic resources with quite different properties, each of which, including language, can make only a partial, incomplete contribution to the action in progress" ( $\mathrm{p}$. $3)$. 
Within this broader methodological framework, participant gestures are a focal point of our analysis. The representational affordances of gesture are especially useful in interpreting learning situations because they may, "take a transitional role between in the acquisition of scientific language" (Roth, 2002, p. 552). In situations where learners have not mastered this language, attending to gesture may thus provide insight into their emerging understandings. In mathematics and physics education specifically, a variety of findings from the past decade have given us new knowledge of learning processes by attending to learners' bodies and gestures.

Scherr (2008) emphasizes two features of gesture analysis that prove to be especially valuable in the setting of physics education: First, gestures can indicate emerging ideas that students are not yet able to fully articulate. The nature of physics relies on multiple verbal and diagrammatic representations and students often struggle to use those representations in classrooms (Ainsworth, 2008; Henriksen \& Angell, 2010). Attending to gesture therefore illuminates how students bridge the gap between lack of knowledge and mastery of a particular physics domain.

Second, gestures provide sensorimotor information that can influence and prompt idea construction. As physics describes fundamental phenomena in nature, one important aspect of embodied cognition in physics classrooms is therefore based on the assumption that learners' bodily experience of nature mediates their own conceptual understanding. Scherr suggests that a student thinking about a projectile in motion "might simply feel what the object would do" (Scherr, 2008, pp. 4-5). Roth (2002) also demonstrates how such gestures in high school physics classrooms support the emergence and development of scientific language. 
However, this feature of embodiment in physics might run into conflict with the highly abstract domain of general relativity: Taking the stance that students "perform gestures that are close to being enactments, having many features in common with physical actions performed on the external environment” (Scherr, 2008, p. 5), gestures could prove futile or even obstructive in the setting of curved spacetime. In particular, the challenge is not simply in producing a material representation of an abstract concept, but that the interpretation of our sensory experiences of gravity within the current conceptual frame may actually contradict the concept. In the episode presented in this study, we observe instances when students make (three-dimensional) gestural inferences about the curvature of (four-dimensional) spacetime that actually seem to confine students to a particular conceptual framework.

We thus argue that imagining is mediated by gesture and material representations (Nemirovsky, Kelton, \& Rhodehamel, 2012). We also argue that these gestures and representations, as mediators of imagining, can simultaneously serve communicative and cognitive functions (Alibali, M. W., Heath \& Myers, 2001; Steier, 2014). Situations involving learning about general relativity thus invite a methodological approach that accounts for these embodied perspectives for a variety of reasons. These include the prevalence of spatial and bodily metaphors, patterns of gesture use in domains of physics and mathematics, and conflicts between new conceptions of gravity and perceptual and sensory experiences with gravity in the world.

\section{Research Setting / Methods}

Before analyzing a conversation between two upper secondary students that work with concepts of curved spacetime in a physics classroom, we want to contextualize the 
scene by presenting the background of the research project and our methods of data collection.

\section{Project Background}

This study has been conducted within the larger design-based research project ReleQuant. ReleQuant was established to develop new ways of teaching modern physics through web-based learning modules and to investigate students' learning processes in general relativity and quantum physics (Bungum, Henriksen, Angell, Tellefsen, \& Bøe, 2015; Henriksen, et al., 2014). The project emphasizes qualitative and philosophical aspects of modern physics and is based on a sociocultural view of learning that understands conceptual development as a process influenced by social interactions (Vygotsky, 1978; Rasmussen \& Ludvigsen, 2010). In particular, use of language plays an important role in learning physics and the module encourages students to discuss key topics repeatedly through structured interactions. Both the sociocultural stance of the project design and its reliance on language and qualitative descriptions are likely to create an environment that fosters explorations among students in which one can observe imagining in action.

Being a design-based research project, the goal of ReleQuant has been to find workable solutions to teaching and learning in general relativity. Through the development of resources for the actual school setting, the design-based research (DBR) framework builds a bridge between educational research and the physics classroom. The approach of DBR relies on repeated rounds of development and testing in close collaboration with practitioners. In ReleQuant, teachers and teacher students from four Norwegian schools have been involved in the development of the resources. The schools 
are partner schools of the research project and are regarded as having high-achieving students in national comparison. Based on a pilot program (Ytterhaug, 2015), the development of the general relativity module has undergone three rounds of testing and refinement (Kersting et al., 2018). The iterations have been based on data coming from student texts, audio and video recordings, field observations, and focus group interviews. In line with the sociocultural stance of the project, the learning resources often ask students to discuss key concepts of general relativity in pairs or small groups. Thus, the data set comprises a great amount of audio and video material from these student discussions. The episode of this study was collected during in the first round of trialing and presents an extended pair discussion on the concept of curved spacetime which was used to inform later design iterations.

\section{Data Collection and Analysis Method}

The module on general relativity was introduced to final year students (18-19 years old) in six Norwegian upper secondary physics classrooms in February and March 2016. Teaching comprised two units of 90 minutes each and was conducted by the regular physics teachers that had previously attended a seminar on the project material. The general relativity module consisted of four 'chapters,' one of which introduced the notion of curved spacetime. In this particular chapter, students were presented with the key idea of general relativity: Mass curves spacetime, curvature influences the movement of mass, and gravity can be interpreted as a geometric phenomenon.

This study is based on video recordings collected from 3 classrooms and was supplemented by student texts, audio recordings, as well as observations and field notes from all six classrooms. Given that the abstract notion of four-dimensional spacetime is 
likely to give rise to imaginative conflicts, we focused on the spacetime chapter during our analysis in particular For this present study, our interest in processes of imagining led us thus to identify segments of video data in which students were working explicitly with the concepts of curvature and spacetime. These excerpts were transcribed and translated from Norwegian. Our analysis applied methods from the interaction analysis tradition (Jordan \& Henderson, 1995; Furberg et. Al., 2013). We thus focused on the turn by turn sequencing of utterances in relation to bodily and gestural practices, as well as orientations to material resources (computers, texts, etc.). The supplementary data including observations and collected student productions allowed us to situate these interactions in the context of institutional practices such as teaching styles and classroom organization. We viewed the excerpts repeatedly over several rounds, beginning with rich descriptions of the students' actions. In subsequent rounds of analysis, we applied theoretical concepts related to imagining (Linell, 2009). Both physics educators and learning scientists helped to discuss findings in round-table sessions with particular attention to the bodily and material practices of participants (Streeck et al., 2011). These methodological choices were in line with our interest in the complexities of situated meaning making processes.

We selected one particularly rich episode to focus on for this study as illustrative of imaginative processes. While many of the small group discussions addressed movement in curved spaces, we identified this pair of students as particularly engaged and knowledgeable, and their interaction stood out because the group continued their discussion through a class break. The focal episode is not representative of all interactions of the various groups, but it does capture in a relatively short time frame 
many of the common challenges that other groups likewise encountered. The particular episode was selected because the group used a variety of representational and imaginative efforts in a short period of time, and they attempted repeatedly to crosswalk different conceptual systems to make sense of gravity and curved spacetime

\section{Episode: An extended conversation about gravity and spacetime}

In this conversation, we see two boys, 'Ben' and 'Sam', sitting at the front of the class on day 2 of the web-based general relativity module. Each has their own laptop on the desk in front of them as well as notebooks and textbooks spread between them. This pair has completed the 'spacetime and curvature' section of the module which concluded with a whole class discussion led by the teacher about Einstein's vs. Newton's theories of gravitation. These two students were quite active in that discussion, and their conversation continued between themselves while the rest of the class took a break.

This conversation is of particular interest because the students show deep engagement with gravity and spacetime, but they struggle to articulate different views of the phenomenon based on classical and modern physics. Their conversation centers partly on a representation of curved spacetime employed in the module, the so-called rubber sheet analogy (Kersting \& Steier, 2018). The rubber sheet analogy compares curved spacetime to a rubber sheet: A heavy object is placed on the stretched sheet and creates a well. In this scenario, the rubber sheet stands for spacetime and the heavy object represents a massive object such as the sun. The movement of marbles that are placed on the sheet is influenced by the well in the middle and this picture illustrates how curvature can alter the path of objects: The marbles move along straight lines that seem curved, because space (i.e., the rubber sheet) is curved. 


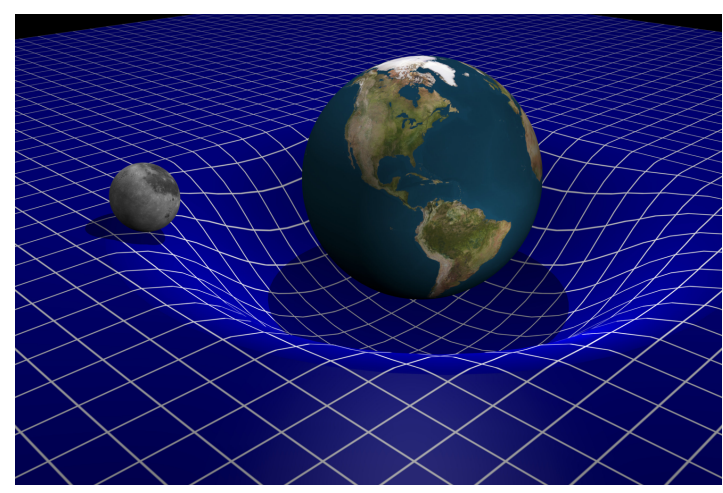

Figure 1: "Curvature of Spacetime - 'Spacetime tells matter how to move; matter tells spacetime how to curve.' J.A.Wheeler" - Screenshot of the introduction to the "rubber sheet" analogy.

\section{Phase 1 - Going Meta: Confronting an Imaginative Challenge on Gravity}

We enter this conversation as Ben begins to question the concept of falling vs.

being at rest. Ben is on the left and Sam is on the right (figure 2).

\section{Excerpt 1.}

\begin{tabular}{|l|l|l|}
\hline & & EXCERPT 1 \\
\hline 1 & Ben & $\begin{array}{l}\text { What I still do not understand is, is that you have to think, you have to think } \\
\text { that you are constantly falling back again to your level. }\end{array}$ \\
\hline 2 & Sam & $\begin{array}{l}\text { Okay, look, what do you mean by your level? I do not understand how you, } \\
\text { because I feel I really have it, like, the models and how it works. I feel I } \\
\text { have it properly. So I do not quite understand what the problem is. Because, } \\
\text { this [here ... }\end{array}$ \\
\hline 3 & Ben & $\begin{array}{l}\text { What happens] (1.8) let's see, i'll just find physics here then ((Flips through } \\
\text { notebook)). What happens when you have that kind of, like here, curved } \\
\text { space? ((Turns to an empty page in his notebook and takes out a pencil) })\end{array}$ \\
\hline 4 & Sam & Yeah \\
\hline 5 & Ben & I do not know how to draw it though. ((Hovers his pencil over the page)) \\
\hline 6 & Sam & $\begin{array}{l}\text { Whatever, now, you don't need to draw the space. Don't draw the space, } \\
\text { only draw the objects. }\end{array}$ \\
\hline 7 & Ben & Ok. Here is Earth ((Speaks slowly while he starts to draw in his notebook)). \\
\hline 8 & Sam & Yeah. \\
\hline 9 & Ben & And here you are, right? \\
\hline 10 & Sam & Yeah \\
\hline 11 & Ben & Then, you jump up. \\
\hline 12 & Sam & Ok. \\
\hline
\end{tabular}




\begin{tabular}{|c|c|c|}
\hline 13 & Ben & Here, you have velocity that way. \\
\hline 14 & Sam & Yes, very small, right. \\
\hline 15 & Ben & $\begin{array}{l}\text { Yes, what is it that, how does curvature get your velocity the other way } \\
\text { again? }\end{array}$ \\
\hline & & $((8$ second pause $))$ \\
\hline 16 & Sam & $\begin{array}{l}\text { Because, you, okay, then you need to think that. ((Starts to search his own } \\
\text { textbook but stops)) }\end{array}$ \\
\hline 17 & Ben & $\begin{array}{l}\text { Here is the curvature like that here, right? Curvature is like that on (all sides } \\
\text { of) the earth. }\end{array}$ \\
\hline 18 & Sam & Yeah? \\
\hline 19 & Ben & $\begin{array}{l}\text { Yes, and when you jump so that you are over that ((Still drawing in } \\
\text { notebook)). }\end{array}$ \\
\hline 20 & Sam & $\begin{array}{l}\text { The thing is that you cannot imagine how to do it. The only thing you need } \\
\text { to do, to think is that it depends whether you fall toward the object or not. }\end{array}$ \\
\hline 21 & Ben & $\begin{array}{l}\text { Yes, but that's what I do not understand; why you fall. There is no reason } \\
\text { why you should fall without gravity. (( } 6 \text { second pause })) \text { Do you see what } \\
\text { I'm trying to say? If there is no gravity? }\end{array}$ \\
\hline 22 & Sam & But the problem here is that for our level, is it not a problem? \\
\hline 23 & Ben & $\begin{array}{l}\text { No here there is no problem ((Points to computer screen, figures } 3 a \text { and } \\
3 b)) \text {. }\end{array}$ \\
\hline 24 & Sam & [Because you must look at \\
\hline 25 & Ben & $\begin{array}{l}\text { Because you follow the space], but I still do not understand if something } \\
\text { stands still there ((Points to computer screen, see figures } 4 a \text { and } 4 b)) \text {. }\end{array}$ \\
\hline 26 & Sam & Yeah. \\
\hline 27 & Ben & You can still think that there is something that pulls you in. \\
\hline 28 & Sam & Yeah. \\
\hline 29 & Ben & That is, you must move first for it to work. \\
\hline
\end{tabular}

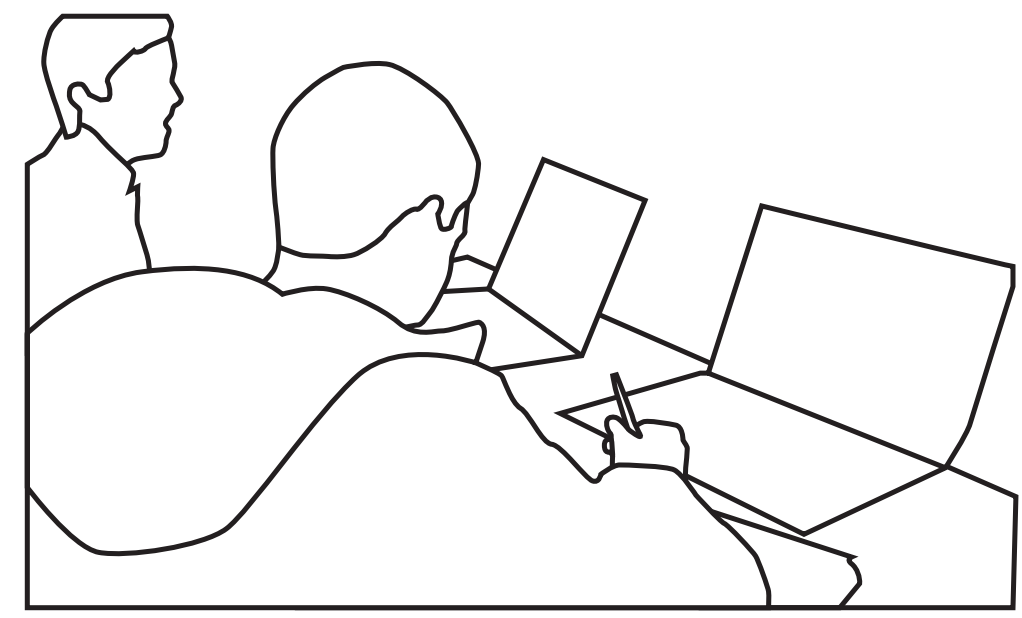

Figure 2: Ben (left) and Sam (right) work together in front of their computers, textbooks, and notebooks on a desk in the front of the classroom. 


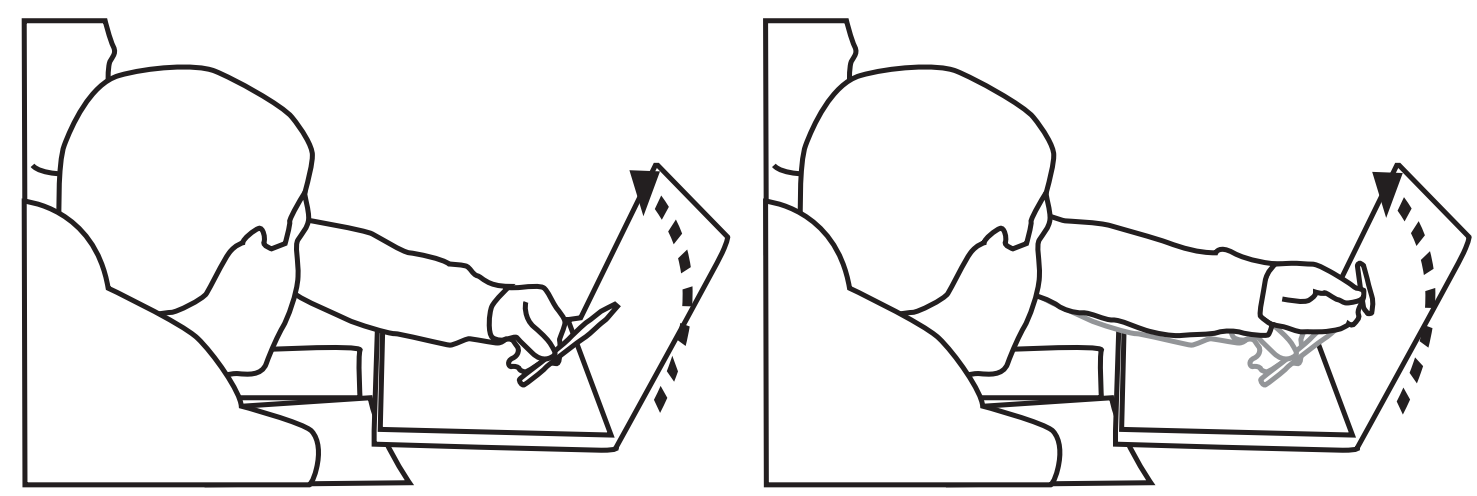

Figure $3 \mathrm{a}$ and $3 \mathrm{~b}$ : Ben traces a curved trajectory on his computer screen (turn 23)
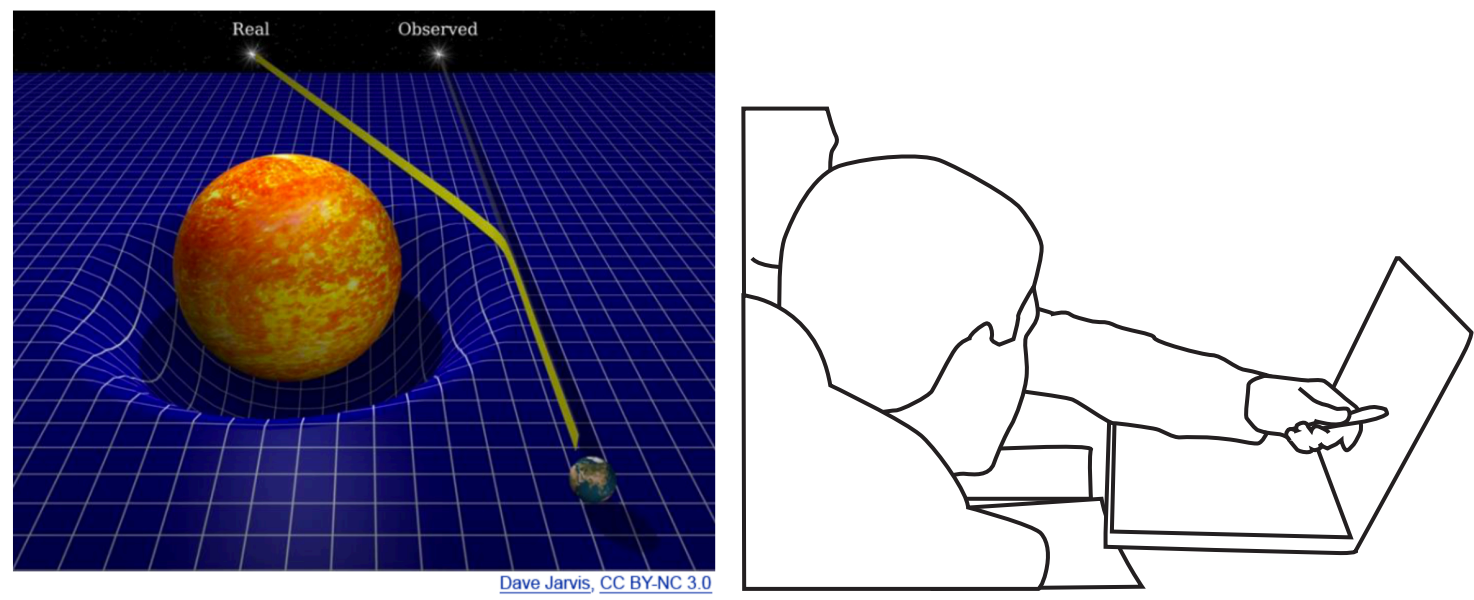

Figure 4a: The computer image on Ben and Sam's screen shows the gravitational bending of light around the sun. Figure 4b: Ben points at the point of deflection (turn 25)

Analysis 1. In this excerpt, we identify an initial phase of metaimagining that sets the stage for the shared exploration to follow. The activity of metaimagining begins with the attempt to address the imaginative challenge of falling, but this is not a trivial task. Imaginative work is required just to ask the question. Ben attempts to articulate what confuses him about "falling" in relation to gravity according to Einstein, but Sam does not understand what the problem is (turns 1-2). With this first exchange, a dynamic emerges that largely shapes the rest of the conversation. Ben is trying to articulate a point 
of confusion while Sam appears less critical towards these tensions of curved spacetime in relation to gravity.

Ben takes out his notebook and begins to draw ${ }^{2}$ as he still tries to formulate his question (turn 3). Then, Ben realizes that he doesn't know how to draw curved spacetime (turn 5). At this point, Ben has shifted modalities from a verbal attempt at question asking to a visual attempt through drawing. His challenge in drawing curved space is actually thus tied to his trouble in imagining it. From the perspective of imagination as a collective activity, we can view Ben as attempting to produce a shared object to continue the process of imagining.

Sam moves the discussion forward by pointing out that Ben doesn't need to be able to draw spacetime, only the objects (turn 6). Sam will express variations of this sentiment throughout the conversation. This tension between depicting curved spacetime itself, and merely understanding the effects of such distorted spacetime on objects, is key to how we approach these students' meaning making.

Ben then shifts his depiction by placing himself in an imagined scenario. He begins to present the scenario of a person jumping from the surface of Earth (turns 7-10). Ben takes the Earth and himself as a starting point, and proposes that "you jump up" with a velocity (turn 11). He then is able to formulate the question: "How does curvature get your velocity the other way again?" (turn 15). The sequence up to this point reflects the situational nature of being able to pose a question (Steier, 2014).

Sam then makes their processes of imagining a relevant aspect of the conversation by responding that you "cannot imagine how to do it" and that you just need to be able to

\footnotetext{
2 The video material unfortunately does not allow us to see these drawings clearly, we can only observe when drawing is taking place and when they are being attended to.
} 
describe the phenomena (turn 20). But simply not imagining the concept does not seem to be a satisfactory resolution for Ben as the visualization of this concept seems intimately tied to his understanding. Ben is then able to clarify his question with a concrete example, saying that he still does not understand why you are falling without gravity (turn 21). By discussing concepts of curvature in terms of velocity and the phenomenon of falling, Ben and Sam have now begun to attempt to integrate Einsteinian concepts into their Newtonian framework. Encountering difficulties, they then recognize this as an imaginative challenge. This attempt characterizes a first stage of metaimagining. There is a six second pause while Ben waits for Sam to reply. Ben starts to restate his question (turn 21) and then Sam tries to clarify what the actual problem in Ben's given example is (turn 22). Ben disagrees and explains that he does not have a problem with the example given in the module which presents the gravitational bending of light as it passes the sun. He points to the screen with his pen and traces the trajectory (turn 23, Figures 3a,b) of the bending ray of light. However, as the two talk over each other, he again clarifies that he is asking about an object at rest. Ben says "I still do not understand if something is at rest there" as he points with his pen to the point of deflection on the diagram (turn 25, Figure $4 a, b)$.

Ben continues, "you can still think that there is something pulling you in" and adds that "you must first move for it to work". Ben has replaced the concept of gravity with the ambiguously defined something that pulls you in. This replacement can be viewed as an attempt to align his earlier understandings of gravity as a force that pulls with the newly introduced theory of gravity in general relativity. At this point, Ben seems to reach a comfortable formulation of his question, which we would restate as: When an 
object is at rest, how does gravity in the form of curvature make it fall/move? The notion of "at rest" is an important as the distinction between movement and rest seem to be a central, if not fully articulated, aspect of Ben's question.

Ben has also made use of the figure from the module in an interesting way. He is not merely tracing the trajectory of the diagram, as it was perhaps intended to be used. Instead, he is, in a sense, borrowing the scenario presented by the diagram as a setting to reformulate his question and place an object. He is inscribing the diagram with a new situation to ask what happens when an object is at rest "here." This action is an example of appropriating the available resources to mediate their own imagining. This placing of one's self into a representation through talk, gesture, and imagination, referred to as "interpretive journeys," is reflective of a way that physicists communicate and experience physical processes (Ochs, Jacoby, \& Gonzales, 1994). Thus Ben and Sam actually have begun to engage in some of the practices involved in doing physics.

Ben has now actually proceeded through several forms of bodily action including drawing an imagined scenario that places himself as the object under the influence of gravity, as well as gesturing over an illustration from the module. Nemirovsky and Ferrara refer to this kind of collage of depictions in imaginative activity as "juxtaposing displacements" (2009). The point is not that each is a new approach from Ben's previous abandoned attempts to express spacetime, but that by continuously constructing depictions that shift focus and reference points, a fuller picture of the imaginative processes are communicated and revealed. This challenge is perhaps the crux of their task - representing four dimensions using only the available three-dimensional tools. Ben and Sam seem to find themselves in a situation similar to Hutchins' (1995) Micronesian and 
Western navigators as they try to move between incompatible frameworks. They are attempting to imagine something that cannot be imagined in their current conceptual framework of classical physics.

\section{Phase 2 - A Pattern of Metaimaginative Productions}

As the conversation continues, we see a particular pattern of metaimagining unfold that bounces back and forth between depicting concepts and attempting to integrate these depictions into their conceptual frameworks. The boys display various metaimaginative productions, i.e., practices that are treated as mediators to address their imaginative challenges. They then, in turn, employ these productions to try to shift between the Newtonian and Einsteinian frameworks. In the course of the episode, the series of depictions of "curvature" becomes increasingly sophisticated and moves to higher levels of abstraction while Ben and Sam address the limitations of their imagining.

We enter back into their conversation after several turns about the challenge of imagining objects "falling" due to curvature. Sam has again just clarified that gravity is curved space, but that one cannot imagine it.

\section{Excerpt 2.}

\begin{tabular}{|l|l|l|}
\hline 38 & Sam & $\begin{array}{l}\text { EXCERPT 2 } \\
\text { You just have to accept it. The point is, you just have to accept, because you } \\
\text { have no problem accepting. Look here, if this is the sun, right, and this is } \\
\text { the Earth, then the earth falls toward the sun all the time ((Takes out his own } \\
\text { notebook and starts to draw a small diagram)). It's falling towards it. You } \\
\text { just have to imagine that it's the same thing happening to you, just that, it's } \\
\text { hard for you to understand. [That is, you just think that }\end{array}$ \\
\hline 39 & Ben & $\begin{array}{l}\text { More or less but,] then maybe you should. I realize that this here falls right } \\
\text { in because there is a curvature, right? ((Points to Sam's notebook)) }\end{array}$ \\
\hline 40 & Sam & $\begin{array}{l}\text { Yeah, then you just have to imagine that it's something like 2D there. You } \\
\text { can just draw yourself 2D like that, right, [and ... }\end{array}$ \\
\hline
\end{tabular}




\begin{tabular}{|c|c|c|}
\hline 41 & Ben & $\begin{array}{l}\text { Yes], but that one there ((Pointing again to sketch in Sam's notebook)), the } \\
\text { only reason I realize that the curvature works is because it has velocity(.) } \\
\text { Without velocity, why should the curvature work? }\end{array}$ \\
\hline 42 & Sam & $\begin{array}{l}\text { What do you mean now? Without velocity? The velocity is that way } \\
((\text { Draws over his sketch })) \text {. }\end{array}$ \\
\hline 43 & Ben & Yeah? \\
\hline 44 & Sam & Yeah. \\
\hline 45 & Ben & And then the curvature works because it's changing [(trajectory?) \\
\hline 46 & Sam & $\begin{array}{l}\text { No, no, put a ball] in a curved thing. Won't it fall down regardless of } \\
\text { whether it has an initial velocity because...? ((Sam uses his hands to depict } \\
\text { a ball on a curved surface, figures } 5 a \text { and } 5 b))\end{array}$ \\
\hline 47 & Ben & $\begin{array}{l}\text { Yes, it falls down ((Depicting curved path with his left hand, figure 6)) } \\
\text { because there is gravitation, which is pulling downwards. }\end{array}$ \\
\hline 48 & Sam & $\begin{array}{l}\text { Yeah. ((6 second pause)) But the point is that the space itself is curved. It } \\
\text { means that it has no choice but to go that way ((Performs similar gesture to } \\
\text { turn } 46 \text { of a ball on a slope, figures } 7 a \text { and } 7 b)) \text {. Okay, okay, I understand. } \\
\text { Okay I am also confused about it but do not understand why you accept that } \\
\text { if it goes that way it should go down (Points back to sketch in his } \\
\text { notebook)). }\end{array}$ \\
\hline 49 & Ben & $\begin{array}{l}\text { Because then there is more resistance to go up than down than there is to } \\
\text { just go. }\end{array}$ \\
\hline \multirow[t]{2}{*}{50} & Sam & $\begin{array}{l}\text { I think the last part is completely wrong. I do not think there is resistance, I } \\
\text { think it's just the straight line has been curved like that ((With his palm } \\
\text { facing inward, curls his fingers in, figures } 8 a \text { and } 8 b)) \text {. }\end{array}$ \\
\hline & & $\begin{array}{l}((\text { The teacher approaches and stands quietly in front of Ben and Sam's } \\
\text { desks }))\end{array}$ \\
\hline 51 & Ben & $\begin{array}{l}\text { Yes, but if you think that you have one like that coming here, so it is easier } \\
\text { to turn around like that, that's what I think, right ((Points back to his earlier } \\
\text { notebook sketch)). }\end{array}$ \\
\hline 52 & Sam & $\begin{array}{l}\text { I think that as such, sort of the straight space is deflected, so when the } \\
\text { particle goes straight then it really doesn't go straight, because the space is } \\
\text { bent over ((Sam extends his right hand with palm facing downwards and } \\
\text { then tracing a path with his left index finger, figures } 8 a-c))\end{array}$ \\
\hline 53 & Ben & But, when you stand still. \\
\hline 54 & Sam & Yes. \\
\hline 55 & Ben & So it will not help me (with) why you then still fall. \\
\hline 56 & Sam & $\begin{array}{l}\text { No, no, but you fall all the time, even when you are standing on Earth, it's } \\
\text { just that there is resistance up again ((points up with his right hand }) \text { ). So } \\
\text { you're still falling, you're like falling all the time. }\end{array}$ \\
\hline 57 & Ben & $\begin{array}{l}\text { Yes, but it's hard to understand that you fall without a gravitational force. } \\
\text { But only with curvature. }\end{array}$ \\
\hline
\end{tabular}



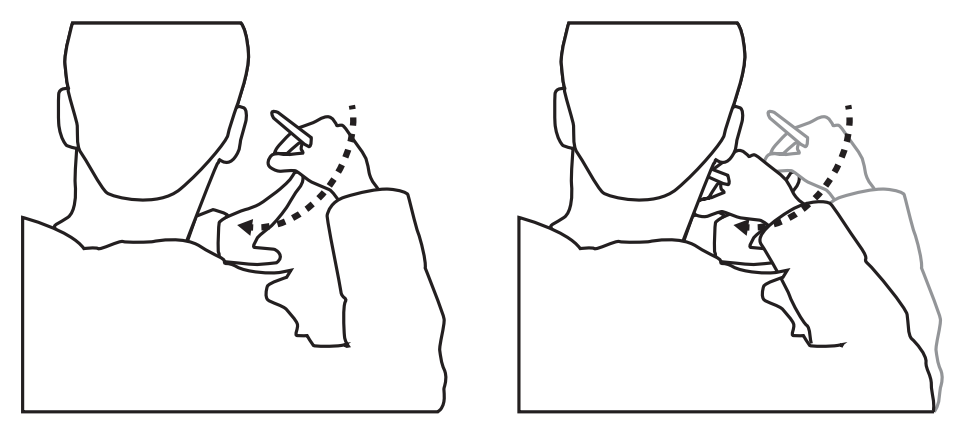

Figure 5a, and 5b: Sam depicts an imaginary ball roll rolling down a curved slope.

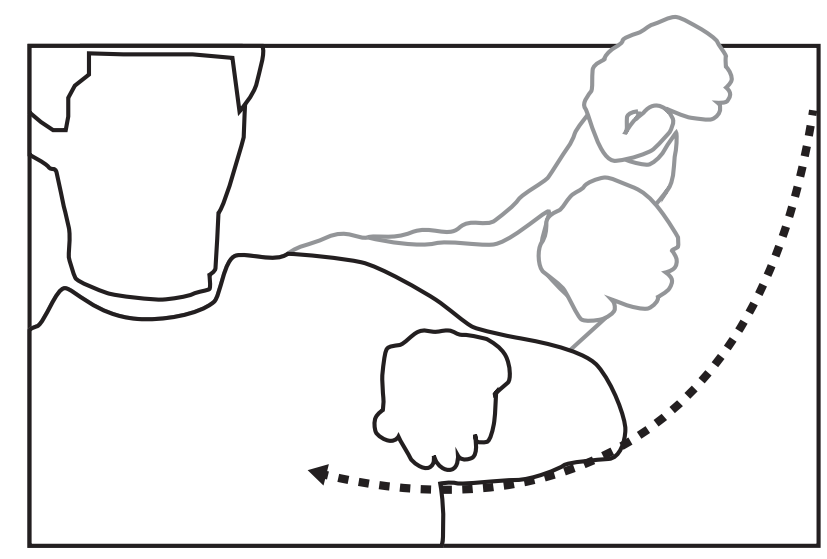

Figure 6: Ben depicts the curved path of an imaginary ball (turn 47)
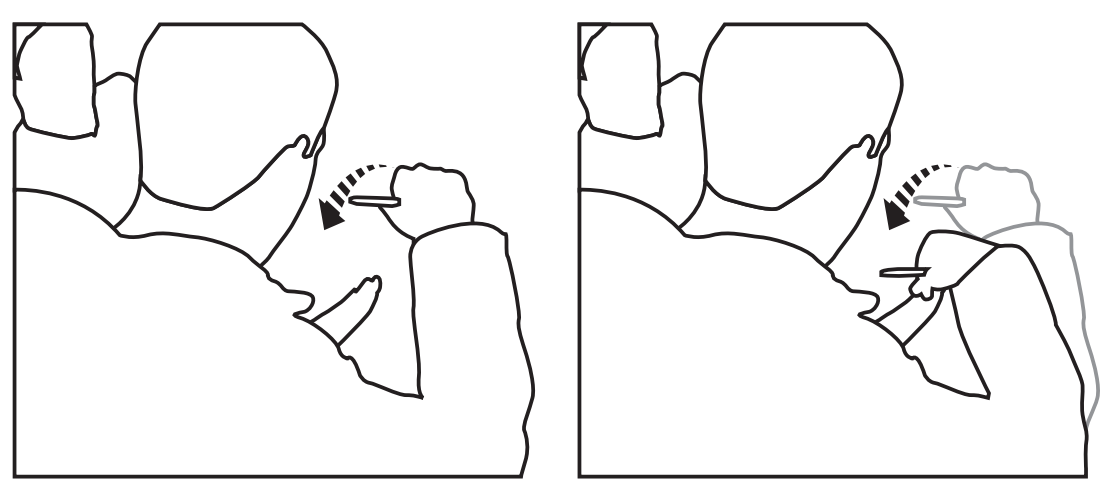

Figure $7 \mathrm{a}$ and $7 \mathrm{~b}$ : Sam repeats a similar gesture to Figures $5 \mathrm{a}, \mathrm{b}$ to depict the curvature of space (turn 48). 

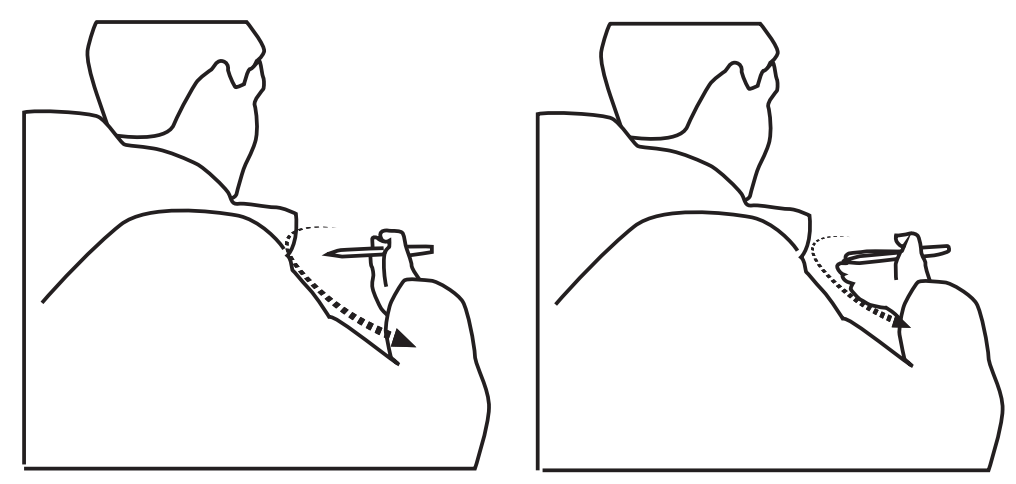

Figure 8a and 8b: Sam performs the curving of a straight line (turn 50).
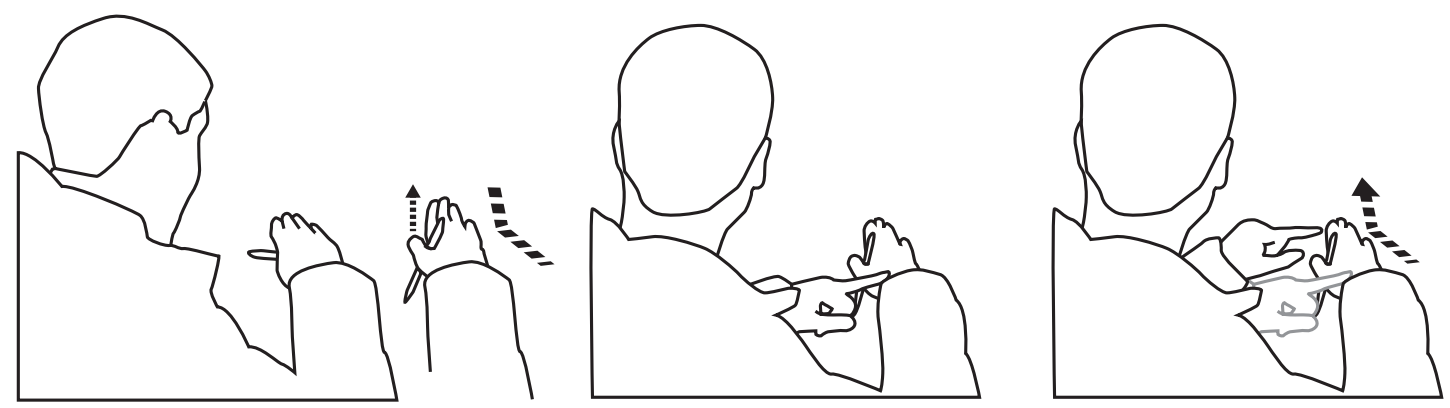

Figures 9a, 9b, and 9c: Sam depicts how a particle's trajectory is deflected by bent space (turn 52). 
Analysis 2. During the first phase of their conversation, Ben and Sam have set the stage for their shared exploration of curved spacetime by acknowledging the limitations of their own imagining. As their conversation unfolds, the instructional material further prompts Sam's line of argument. The module presents the earth circling around the sun as an introductory example to show how one can interpret the classical force of gravity in a new way. Sam tells Ben that he doesn't have a problem understanding the earth as falling towards the sun (as he draws this example). He then says, "You just have to imagine that it's the same thing happening to you, just that, it's hard for you to understand" (turn 38). Sam animates his own drawing and uses a thought experiment to build a bridge between Ben's personal understanding of gravity, which corresponds to him standing firmly on the ground, and the earth-sun-example that explains gravity on a larger scale. Here, we identify a common pedagogical strategy as one particular mediator of metaimagining. Sam and Ben have agreed earlier in their conversation that they understand the movement of the earth around the sun. The fact that orbital motion in classical physics is often explained by stating that a satellite falls constantly towards the earth could help them accept the new way of thinking about gravity in this situation.

By reducing the number of dimensions, Sam draws on another metaimaginative production and tries to simplify the problem as is common practice among physicists (turn 40). Ben does not respond to this proposal but instead restates an earlier question, "The only reason I realize that the curvature works is because it has velocity. Without velocity, why should the curvature work?" (turn 41). This formulation differs from his earlier question because he now talks about velocity instead of movement. Ben is still distinguishing objects "at rest" from orbiting objects with a given velocity. Curvature 
seems to be tied to movement. That is, he is wondering how you can apply/see curvature from only a single static point.

Here, we might observe another instance of the fundamentally classical reference system inhabited by Ben. He might try to incorporate the idea of curvature in an explanation of gravity, but in trying to make sense of the circular movement of the earth around the sun, he arrives yet again at the necessity of introducing velocity. His reliance on the Newtonian framework of representing gravity limits the sorts of inferences that make sense. This struggle is reminiscent of the Micronesian navigator who could not initially make sense of intersecting lines of Western navigation. The problem of moving to an Einsteinian frame of explanation becomes apparent in Ben's next utterance. He proposes that the curvature is working by changing the trajectory of the jumping figure. It seems the change Ben is referring to here is from 'up' to 'down' as the figure jumps and returns to Earth. Ben seems to remain within a classical physics framework, because now he replaces verbatim the concept of force with the concept of curvature. In classical mechanics, an object will only change its trajectory if a force acts upon it and Ben now ascribes this property to curvature (turn 45).

Sam immediately interrupts Ben, saying "no, no" in order to try a different metaimaginative production by introducing an embodied thought experiment. Sam speaks more forcefully now, as he is seemingly quite invested in reaching a shared understanding with Ben. He now invites Ben to "put a ball on a curved thing." $\mathrm{He}$ simultaneously forms a slope with his left hand and uses his right hand to place an imaginary ball at the top (turn 46, Figures 5a,b). This gesture is the starting point to a series of different depictions of curvature: In a short series of turns, Sam's hand depicts a 
physical slope, an abstract curved line, and the curvature of spacetime itself. He asks "Won't it fall down regardless of whether it has an initial velocity because...?" (turn 46) and Ben interrupts, confirming "yes, it falls down" only to explain this fact with the presence of gravity (turn 47). Here, Ben again shares an interpretation of the proposed scenario from within a classical framework. The metaimaginative productions and attempts to crosswalk conceptual frameworks are thus intimately intertwined.

By posing a "rhetorical" question, it seems as if Sam wants to draw attention to the apparent conceptual tension that an object needs to be moving in order to be influenced by curvature. Sam now relies on the everyday example of a curved slope that he and Ben can easily relate to: A ball that is placed on a slope will roll down regardless of whether it has an initial velocity or not. By confirming "yes, it falls down", Ben signals that he accepts Sam's simplified representation of spacetime as a shared object for further probing their understanding. However, Ben now adds "it falls down because there is gravitation, which is pulling downwards". As he enunciates the word "because" he traces the trajectory of the curved path of this imaginary ball (Figure 6, turn 47).

This is a crucial moment and we can highlight the introduction of this new analogy of a ball on a slope as a key continuation of metaimagining. That is, in the given situation repeated from above-imagine my hand is now a ball so that you can imagine how gravity works - the goal of the students in imagining what gravity is like is crucial for making sense of this new imaginative act of pretending that my hand is now a ball. Regardless of its productivity in aligning the conflicting conceptual frameworks, the introduction of this new imaginative situation can be viewed as a creative attempt to make sense of the initial imaginative challenge. The use of such bridging analogies (i.e., 
the introduction of a new analogy to make sense of a more complex analogy) is another instance of a tactic used by physicists in explaining abstract phenomena (Clement, 1993). Moreover, Ben and Sam have made a problematic aspect of the rubber sheet analogy relevant: the analogy makes use of two different concepts of gravity and relies on classical gravity to make the analogy of "Einsteinian" gravity work. Here, we can see how the conflict between two reference systems act as a catalyst for metaimagining. Sam attempts to resolve this tension by elaborating, "but the point is that the space itself is curved. It means that it has no choice but to go that way" (Figures 7a,b, turn 48). Sam again uses his hands to form the same depiction of a curved slope and imaginary ball, but this time he is representing the curvature of spacetime itself. Here Sam returns to the language of curved spacetime.-There is a two second pause while they both appear to be thinking and we see a confused expression on Ben's face.

Next, Sam notes that he is "also confused", acknowledging that his own understanding is fragile. This is a significant moment because it positions the pair as collaborators in a shared state. Sam invites Ben to explain the conflict further, emphasizing that he is confused because the imaginary ball could follow several directions on a curved surface if there is no immanent (classical) gravitational force that dictates a "downward" movement of the ball.

Ben begins to speak slowly and tentatively as he tries to make use of the somewhat vague and everyday notion of resistance (turn 49). Here, it is not clear which physical concept Ben refers to. He might treat inertia as a fundamental notion in classical physics that describes the resistance of an object to a change in its motion. Sam seems to take offence at the mentioning of resistance (as an apparently invalid concept) and says 
that he thinks this is "completely wrong" (turn 50). He says "I do not think there is resistance, I think it's the straight line itself that has been curved like that" (turn 50). While saying this, Sam first draws over the same drawing and then uses his right hand to depict curvature by curling his fingers inwards (Figure 8a,b). It is also interesting to note that both Ben and Sam only talk about up and down movement when talking about gravity remaining in a classical frame (turn 48-49).

The class teacher seems to hear the confusion and walks over to stand in front of the pair. While briefly acknowledging the teacher, Ben restates his understanding to Sam by gesturing over his notebook (turn 51). He seems to be again tracing the trajectory of an object around a more massive object.

Sam then offers his own explanation (turn 52), "I think that as such, sort of the straight space is deflected, so when the particle goes straight then it really doesn't go straight, because the space is bent over." Sam uses his right hand, fully extended, palm down, to depict straight space. He then points his fingers up to show the 'deflection.' He uses his left hand to show a particle following this deflection (Figures 9a,b.c).

Ben returns to the concept of motion by saying "but when you stand still" (turn 53), and notes that Sam's explanation does not help him understand why you still fall. He is again returning to reference his initial question (excerpt 1). Ben seems to be focusing on Sam's demonstration of a particle following a straight trajectory, when he actually wonders about a particle at rest, which does not follow a trajectory (at least from a classical frame, it follows a path in the time-direction after all).

Sam says "No no, but you are falling all the time, even when you are standing on Earth." He says "it's just that there is resistance up again" while pointing upwards. Here, 
Sam probably refers to the normal force that is opposed to the gravitational force in classical mechanics. This insight that one is always in a sense 'falling' through spacetime is perhaps the key insight that Ben has not acknowledged and that Sam has perhaps not clearly articulated. However, even Sam combines notions from classical and modern physics in this explanation.

Ben is still confused and says "yes, but it's hard to understand that you fall without a gravitational force. But only with curvature.” (turn 57). Ben thus repeats his previously stated idea tying gravity to falling. He is able to accurately state the essence of general relativity, but he is unable to align this with the classical interpretation of his perceptual understanding. The excerpt ends as the students are guided in a new direction by the teacher.

\section{Discussion}

Looking across this episode, we can see that analytic attention to the interactional aspects of imagining gives us insight into the ways that the participants deal with a particularly abstract and challenging scientific concept. Within this lens, we can identify a variety of imaginative activities performed by the participants. We also introduced metaimagining as a concept to help us unpack and make sense of the ways that participants shift across and between these activities as they confront their own imagining and limitations thereof. In light of our findings, we want to develop this concept further and discuss its potential to improve instructional practices in general relativity and science education more generally. The selected excerpts we analyzed demonstrate two phases of metaimagining. 
Initially in the first phase, a difficult imaginative task is revealed to be a tension between conceptual frameworks. We saw two students confronting an imaginative challenge about spacetime, and the excerpt largely consists of Ben trying to articulate a question, followed by Sam contributing various attempts to address or contest this question. Between these attempts, Sam frequently notes that Ben "cannot imagine" the thing that he is trying to understand and must just "accept" it. This cycle of frustration and engagement sets the stage for a shared attending to the context of their imagining. The struggle to articulate and conceptualize the notion of spacetime reveals the tensions between Newtonian and Einsteinian frameworks as well as the imaginative processes used to deal with such conceptual challenges. The conversation prompts a variety of metaimaginative productions, i.e., explanatory and representational activities that guide the shared exploration of the relativistic concepts in the second excerpt.

In naturally occurring situations, metaimagining emerges most likely as the result of a tension or contradiction between different views of the world. In this sense, Ben and Sam resemble Hutchins' two navigators. The two boys struggle to align their experiential understanding of gravity, as established by the classical Newtonian framework, with the conceptual framework of Einstein. Hutchins noted that "While the Caroline Island navigators are fully capable of imagining and even drawing charts of their island group, these conceptions are not compatible with the moving-island and star-bearing conceptions they use while navigating" (Hutchins, 1996, p. 83). Both the Micronesian and the Western navigator have to conceptualize the same experience (of seeing two islands but not the third). However, their reference frames to conceptualize these experiences are so diametrically opposed that they become mutually exclusive; their 
respective understanding seems to be contradictory in light of the other conceptual frame. Similarly, Ben and Sam can draw on Einstein's theory to explain gravity, but this explanation seems incompatible with their understanding of gravity when navigating their everyday world that is characterized by a steady pull towards the Earth.

The conflict of Ben and Sam's experiential understanding of gravity with the conceptual domain of general relativity is worth exploring further. Is it their bodily experience of gravity or rather their experience conceptualized in the frame of Newtonian physics that contradicts the concept of curved spacetime? Since most of us have been exposed to the ideas of Newton, the sensation of gravity on our feet might "feel" like a force. However, what we experience is rather an artifact of us following a path through curved spacetime. Metaimagining is required to crosswalk such different conceptual frames that entail different explanations for the same phenomenon. To illustrate this ontological subtlety further, we draw on a famous anecdote of Wittgenstein questioning the validity of our perception of the movement of the Earth and the Sun:

He [Wittgenstein] once greeted me with the question: 'Why do people say that it was natural to think that the sun went round the earth rather than that the earth turned on its axis?' I replied: 'I suppose, because it looked as if the sun went round the earth.' 'Well,' he asked, 'what would it have looked like if it had looked as if the earth turned on its axis?' (Anscombe, 1959, p. 151)

Then in the second phase illustrated in episode 2 , new layers of metaimagining unfold as an alternating pattern of such productions and depictions followed by attempts to integrate these productions to the alignment of the conceptual frameworks. Comparing this phase again to Hutchins' navigators, we realize that Beiong's effort to 
simultaneously imagine both directions of the journey between two islands may be viewed as a metaimaginative production to integrate the competing reference frames. The difference is that this effort proved satisfactory, whereas Ben and Sam proceeded through a sequence of such attempts without a clear resolution.

Looking more closely at these attempts, the methodological lens of embodied interaction allows us to highlight several different bodily depictions of the troublesome concept of curvature. In the span of about one minute, starting with Sam's introduction of a ball on a slope, we see at least 4 distinct depictions of curvature. Each of these depictions is oriented differently in space and referring to different aspects of the concept with changing referents. Hands shift from representing a sloping surface, to the trajectory of a particle, to the curvature of spacetime itself. In addition to these gestural depictions, we also see the pair present curvature by drawing in their notebook, and by referencing the diagram from the module.

Collectively, Ben and Sam have performed a variety of attempts to address the initial imaginative challenge of explaining the phenomena of falling through the concept of curvature. In these attempts, they have produced multiple bodily and gestural depictions, sketches, as well as new imagined scenarios, and analogies. Importantly, these attempts build on each other as layers of meaning and not as isolated productions. We interpret many of these productions as reflective of metaimagining: Imagination is required for the pair to perceive these gestures as their referents (e.g. 'imagine my other hand is now a ball'). However, these practices are performed in an attempt to imagine the nature of curved spacetime (e.g., 'imagine my hand is now a ball so that you can imagine 
how gravity works'). The boys' attempt to imagine spacetime thus clearly captures the levels of imaginative practices characterizing metaimagining.

\section{Instructional Implications and Concluding Remarks}

Reflecting more generally on these findings leads us to consider instructional implications which we organize into the four points below. First, it is important to recognize situations where conceptual frameworks are in tension, where crosswalking or integrating such frameworks is required. We positioned these situations as imaginative challenges and as an initial phase of metaimagining. Many of the specific obstacles faced by Ben and Sam can be viewed as a result of this tension and recognizing it as such allows for a more nuanced pedagogical approach than merely reducing the notion of curved spacetime to being a "difficult concept". Framing these tensions in light of competing conceptual frameworks thus prompts the question of how teachers and instructional designers might develop ways to mediate the imaginative processes needed to crosswalk between them, and to bridge the gap between everyday and scientific understanding.

A second instructional implication addresses this question in the specific case of general relativity and the module designed for this study. Although the web-module did in fact present the frameworks as being in tension, this was expressed in terms of Newtonian and Einsteinian definitions of gravity. We saw evidence of the limitations of this presentation when Ben and Sam were able to articulate that gravity is not a force, yet faced difficulties aligning such statements with broader worldviews. Subsequent iterations of the web-module guide the students in relating the two frameworks more directly through a side by side interactive comparison of the different ways that 
Newtonian and Einsteinian frameworks treat the phenomenon explored by Ben and Sam (i.e., "when you fall"). Our hope is that by making this comparison more direct, students will become aware of when aspects of their interpretations of the given phenomenon are rooted in a particular reference system. The results of this development work will be the goal of future studies from within the broader design-based research project.

Third, a specific design implication for the web-module concerns the notion of the time-dimension within Newtonian and Einsteinian physics. The episode between Ben and Sam revealed that imagining the qualities of curvature was closely related to movement. Since the presentation of gravity in the module relied on moving objects (the earth circling around the sun, a ray of light passing the sun), it is not surprising that the question arose about how gravity works for an object at rest. The pair did not express the Einsteinian view that no object will ever be at real rest, because we are moving in time as well: Even though we might seem at rest from a spatial point of view, we are constantly moving along the time-dimension. This insight has had implications for the ongoing redesign of the instructional module as subsequent iterations place a greater emphasis on making the time dimension visible for students. We also now take as a design principle the importance of illustrating gravity not only through objects that are moving through space. Again, this design work and classroom implementation will be the subject of future work.

Finally, we also wish to note that many of the emergent imaginative processes detailed above are reflective of those used in scientific practice. Making the turn towards developing imagination as an object of instruction requires an awareness of this relationship. For example, the metaimaginative productions of Ben and Sam can be 
positioned as common features of scientific practice and discourse such as "interpretive journeys" (Ochs, Jacoby, \& Gonzales, 1994), “embedded skits” (Murphy, 2011), thought experiments, "bridging analogies" (Clement, 1993), in addition to the more general use of talk, gesture, and drawing. A starting point of this study was the observation that imaginative activities are not explicitly addressed in science education, despite the importance of imagination across scientific and mathematical learning and working.

Future research can identify ways for these activities to be introduced as tools for students, perhaps through the concept of metaimagining. Instruction can be developed to guide students in being able to intentionally apply thought experiments, to construct new metaphors, or to perform abstract ideas when confronted with imaginative challenges.

We recognize that the concept of metaimaging emerged in an effort to better understand the quite specific efforts of Ben and Sam to make meaning of general relativity. However, we hope that future work can develop this concept further, in part by identifying other disciplines and concepts that are challenging because they require shifting assumptions and reference frames. We suspect that metaimagining may prove useful for learners facing other concepts in modern physics, such as quantum mechanics, or with notions of infinities in mathematics. It might also shed light on diverse fields such as design or anthropology which depend on attending to conflicting perspectives and reference frames of participants.

Imagining should be an explicit part of instruction - both in specific contexts like learning about general relativity, but more importantly as a transdisciplinary process that can be applied across learning domains. When students are placed in situations in which they are forced to deal with imaginative challenges and paradoxes, it is important for 
them to be able to reflect on and employ their own metaimaginative productions and resources. 


\section{References}

Ainsworth, S. (2008). The Educational Value of Multiple-Representations when Learning Complex Scientific Concepts. Visualization: Theory and Practice in Science Education, 1-15. Http://doi.org/10.1007/978-1-4020-5267-5_9

Alibali, M. W., Heath, D. C., \& Myers, H. J. (2001). Effects of visibility between speaker and listener on gesture production: Some gestures are meant to be seen. Journal of Memory and Language, 44(2), 169-188.

Anderson, K. C., \& Leinhardt, G. (2002). Maps as Representations: Expert Novice Comparison of Projection Understanding. Cognition and Instruction, 20(3), 283321. Http://doi.org/10.1207/S1532690XCI2003

Anscombe, G. E. M. (1959). An Introduction to Wittgensteins Tractatus. New York: Harper Torchbooks.

Azevedo, F. S., \& Mann, M. J. (2017). Seeing in the Dark: Embodied Cognition in Amateur Astronomy Practice. Journal of the Learning Sciences, 00(00), 1-48. Http://doi.org/10.1080/10508406.2017.1336439

Bungum, B., Henriksen, E. K., Angell, C., Tellefsen, C. W., \& Bøe, M. V. (2015). ReleQuant - Improving teaching and learning in quantum physics through educational design research. Nordina: Nordic Studies in Science Education, 11(2), $153-168$.

Disessa, A. A. (1981). An elementary formalism for general relativity. American Journal of Physics, 49(1981), 401.

Egan, K., Judson, G., \& Madej, K. (Eds.). (2015). Engaging imagination and developing creativity in education. Cambridge Scholars Publishing 
Eriksson, U., Linder, C., Airey, J., \& Redfors, A. (2014). Who Needs 3D When the Universe Is Flat? Science Education, 98(3), 412-442. Http://doi.org/10.1002/sce.21109

Gould, R. R. (2016). Why does a ball fall?: A new visualization for Einstein's model of gravity. American Journal of Physics, 84(5), 396-402.

Harrison, A. G., \& Treagust, D. F. (2006). Teaching and learning with analogies : friend or foe. In A. G. Harrison \& S. M. Ritchie (Eds.), Metaphor \& Analogy in Science Education (pp. 11-24). Netherlands: Springer.

Henriksen, E. K., \& Angell, C. (2010). The role of 'talking physics' in an undergraduate physics class using an electronic audience response system. Physics Education, 45(3), 278-284.

Henriksen, E. K., Bungum, B., Angell, C., Tellefsen, C. W., Frågåt, T., \& Vetleseter Bøe, M. (2014). Relativity, quantum physics and philosophy in the upper secondary curriculum: challenges, opportunities and proposed approaches. Physics Education, $49(6), 678-684$.

Hutchins, E. (1996). Edwin_Hutchins_Cognition_in_the_Wild.pdf. Cambridge, MA: M.I.T. Press.

Hutchins, E. (2010). Enaction, imagination, and insight. In J. Stewart, O. Gapenne, \& E. A. Di Paolo (Eds.), Enaction: Towards a New Paradigm for Cognitive Science (pp. 425-450). Cambridge, MA: MIT Press.

Jordan, B., \& Henderson, A. (1995). Interaction Analysis: Foundations and Practice. The Journal of the Learning Sciences, 4(1), 39-103.

Jornet, A., \& Steier, R. (2015). The Matter of Space: Bodily Performances and the 
Emergence of Boundary Objects During Multidisciplinary Design Meetings. Mind, Culture, and Activity, 22(2), 129-151.

Kapon, S., \& disessa, A. A. (2012). Reasoning Through Instructional Analogies. Cognition and Instruction, 30(3), 261-310. Http://doi.org/10.1080/07370008.2012.689385

Kaur, T., Blair, D., Moschilla, J., Stannard, W., \& Zadnik, M. (2017). Teaching Einsteinian Physics at Schools : Part 1, Models and Analogies for Relativity. Physics Education, 52(6), 1-16.

Kersting, M., Henriksen, E. K., Bøe, M. V., \& Angell, C. (2018). General relativity in upper secondary school: design and evaluation of an online learning environment using the model of educational reconstruction. Physical Review Physics Education Research, 14(1), 010130-1-010130-18.

Http://doi.org/10.1103/physrevphyseducres.14.010130

Kersting, M., \& Steier, R. (2018). Understanding curved spacetime - the role of the rubber sheet analogy in learning general relativity. Science \& Education, 27(7), 593-623. Http://doi.org/10.1007/s11191-018-9997-4

Kind, P. M., \& Kind, V. (2007). Creativity in Science Education: Perspectives and Challenges for Developing School Science. Studies in Science Education, 43(1), 137. Http://doi.org/10.1080/03057260708560225

Lakoff, G., \& Núñez, R. E. (2000). Where Mathematics Comes From: How the Embodied Mind Brings Mathematics Into Being (1st ed.). New York: Basic Books.

Linell, P. (2009). Rethinking language, mind, and world dialogically: Interactional and contextual theories of human sense-making. IAP. 
Murphy, K. M. (2004). Imagination as joint activity: The case of architectural interaction. Mind, Culture, and Activity, 11(4), 267-278.

Nemirovsky, R., \& Ferrara, F. (2009). Mathematical imagination and embodied cognition. Educational Studies in Mathematics, 70(2), 159-174.

Nemirovsky, R., Rasmussen, C., Sweeney, G., \& Wawro, M. (2012). When the classroom floor becomes the complex plane: Addition and multiplication as ways of bodily navigation. Journal of the Learning Sciences, 21(2), 287-323.

Http://doi.org/10.1080/10508406.2011.611445

Nishizaka, A. (2003). Imagination in action. Theory \& Psychology, 13(2), 177-207.

Osborne, J., Collins, S., Ratcliffe, M., Millar, R., \& Duschl, R. (2003). What “ideasabout-science" should be taught in school science? A delphi study of the expert community. Journal of Research in Science Teaching, 40(7), 692-720.

Http://doi.org/10.1002/tea.10105

Pelaprat, E., \& Cole, M. (2011). "Minding the Gap": Imagination, Creativity and Human Cognition. Integrative Psychological and Behavioral Science, 45(4), 397-418.

Roth, W. M. (2002). From action to discourse: The bridging function of gestures. Cognitive Systems Research, 3(3), 535-554. Http://doi.org/10.1016/S13890417(02)00056-6

Scherr, R. E. (2008). Gesture analysis for physics education researchers. Physical Review Special Topics - Physics Education Research, 4(1), 1-9. Http://doi.org/10.1103/physrevstper.4.010101

Stannard, W. (2018). Why do things fall ? How to explain why gravity is not a force. Physics Education, 53. 
Steier, R. (2014). Posing the Question: Visitor Posing as Embodied Interpretation in an Art Museum. Mind, Culture, and Activity, 21(2), 148-170. Http://doi.org/10.1080/10749039.2013.878361

Steier, R., Kersting, M., \& Silseth, K. (in press). Imagining with improvised representations in CSCL environments. International Journal of ComputerSupported Collaborative Learning.

Streeck, J., Goodwin, C., \& lebaron, C. (2011). Embodied interaction in the material world: An introduction. In J. Streeck, C. Goodwin, \& C. Lebaron (Eds.), Embodied Interaction - Language and Body in the Material World. Cambridge: Cambridge University Press.

Velentzas, A., \& Halkia, K. (2013). The Use of Thought Experiments in Teaching Physics to Upper Secondary-Level Students: Two examples from the theory of relativity. International Journal of Science Education, 35(18), 3026-3049.

Vygotsky, L. (1978). Mind in Society: The Development of Higher Psychological Processes. Cambridge: Harvard University Press.

Vygotsky, L. S. (1998). The collected works of L. S. Vygotsky. (R. W. Riebe, Ed.) (5th ed.). New York.

Wald, R. M. (2006). Resource Letter TMGR-1: Teaching the mathematics of general relativity. American Journal of Physics, 74(6), 471.

Wheeler, J. A. (1998). Geons, Black Holes, and Quantum Foam: a life in physics. New York: W.W. Norton\&Company.

Ytterhaug, A. S. (2015). Hvordan forstå at jorda går $i$ en rettlinjet bevegelse rundt sola [How to understand that the earth follows a straight motion around the sun] 
(Master's Thesis). University of Oslo. 


\section{Appendix 1}

\section{Transcript Notations}

[text] Indicates the start and end points of overlapping speech.

(\#.0) A number in parentheses indicates the time, in seconds, of a pause in speech.

(.) A brief pause, usually less than 0.2 seconds.

CAPITALS Loud voice

(text) Speech which is unclear or in doubt in the transcript.

((italic text $))$ Annotation of non-verbal activity.

Underlined Emphasis in talk 